\title{
Silicon uptake by wheat: Effects of Si pools and pH
}

\author{
Martina Gocke ${ }^{1 *}$, Wu Liang2 ${ }^{2}$, Michael Sommer3,4, and Yakov Kuzyakov5,6 \\ 1 Department of Agroecosystem Research, BayCEER, University of Bayreuth, Universitätsstraße 30, 95440 Bayreuth, Germany \\ 2 Institute of Geographical Sciences and Natural Resources Research, Chinese Academy of Sciences, 11A Datun Road, Beijing \\ 100101, China \\ 3 Institute of Soil Landscape Research, Leibnitz-Centre for Agricultural Landscape Research (ZALF) e.V., Eberswalder Straße 84, \\ 15374 Müncheberg, Germany \\ 4 Institute of Earth and Environmental Sciences, University of Potsdam, Karl-Liebknecht-Str. 24-25, 14476 Potsdam, Germany \\ 5 Department of Soil Science of Temperate Ecosystems, University of Göttingen, 37077 Göttingen, Germany \\ 6 Department of Agropedology, University of Göttingen, 37077 Göttingen, Germany
}

\begin{abstract}
Silicon (Si), although not considered essential, has beneficial effects on plant growth which are mostly associated with the ability to accumulate amorphous (phytogenic) Si, e.g., as phytoliths. Phytogenic Si is the most active Si pool in the soil-plant system because of its great surface-tovolume ratio, amorphous structure, and high water solubility. Despite the high abundance of $\mathrm{Si}$ in terrestrial biogeosystems and its importance, e.g., for the global C cycle, little is known about Si fluxes between soil and plants and Si pools used by plants. This study aims at elucidating the contribution of various soil Si pools to Si uptake by wheat. As $\mathrm{pH}$ affects dissolution of $\mathrm{Si}$ pools and Si uptake by plants, the effect of $\mathrm{pH}$ (4.5 and 7) was evaluated. Wheat was grown on Si-free pellets mixed with one of the following Si pools: quartz sand (crystalline), anorthite powder (crystalline), or silica gel (amorphous). Silicon content was measured in aboveground biomass, roots, and soil solution 4 times in intervals of $7 \mathrm{~d}$. At $\mathrm{pH} 4.5$, plants grew best on anorthite, but $\mathrm{pH}$ did not significantly affect Si-uptake rates. Total Si contents in plant biomass were significantly higher in the silica-gel treatment compared to all other treatments, with up to $26 \mathrm{mg} \mathrm{g}^{-1}$ in aboveground biomass and up to $17 \mathrm{mg} \mathrm{g}^{-1}$ in roots. Thus, Si uptake depends on the conversion of Si into plant-available silicic acid. This conversion occurs too slowly for crystalline Si phases, therefore Si uptake from treatments with quartz sand and anorthite did not differ from the control. For plants grown on silica gel, real Si-uptake rates were higher than the theoretical value calculated based on water transpiration. This implies that Si uptake by wheat is driven not only by passive water flux but also by active transporters, depending on Si concentration in the aqueous phase, thus on type of Si pool. These results show that Si uptake by plants as well as plant growth are significantly affected by the type of Si pool and factors controlling its solubility.
\end{abstract}

Key words: anorthite / global Si cycle / phytogenic silica / quartz / silica gel / soil Si pools / Triticum aestivum L.

Accepted February 28, 2013

\section{Introduction}

Silicon (Si) is the second most abundant element of Earth's crust (Wedepohl, 1970), with ubiquituous occurrence in marine as well as terrestrial ecosystems. The enormous meaning of the global Si cycle is reflected in its link to the global $\mathrm{C}$ cycle: The continental silicate weathering consumes atmospheric $\mathrm{CO}_{2}$, which is subsequently sequestrated in marine sediments and thus withdrawn from the short-term global $\mathrm{C}$ cycle (Kump et al., 2000). According to mass-balance studies (Tréguer et al., 1995), $\approx 80 \%$ of the Si input into the oceans derive from rivers and thus ultimately from silicate weathering in terrestrial biogeosystems. Knowledge about the quantity of terrestrial Si transport, its spatial and temporal variability and controlling factors is, however, still incomplete (see review by Sommer et al., 2006).

\footnotetext{
* Correspondence: Dr. M. Gocke;

e-mail: martina.gocke@ uni-bayreuth.de
}

The most important terrestrial silicate weathering is connected with soil formation (van Breemen and Buurman, 2002). Soil Si contents range between $<10 \mathrm{mg} \mathrm{g}^{-1}$ in bogs and $450 \mathrm{mg} \mathrm{g}^{-1}$ in some old Podsols (Sommer et al., 2006). The major Si phases in soil are primary minerals inherited from parent material and secondary minerals resulting from soil formation. The latter are subdivided into crystalline phases (mainly clay minerals) and microcrystalline to poorly ordered phases (Drees et al., 1989; Monger and Kelly, 2002). Transformation between those phases is controlled, e.g., by $\mathrm{pH}$, temperature, presence of cations, and organic compounds (Drees et al., 1989; Monger and Kelly, 2002; Gerard et al., 2002), with water as the main medium for Si fluxes in terrestrial biogeosystems. In recent years, the role of plants 
and their roots was discussed as a key factor of silicate weathering and Si fluxes (Berner, 1997).

In soil solutions, the prevailing Si form is silicic acid $\mathrm{Si}(\mathrm{OH})_{4}$. At $\mathrm{pH}<9$, silicic acid occurs as an uncharged monomeric molecule and is available for plant uptake ( $M a$ and Yamaji, 2006). Concentrations of $\mathrm{Si}$ in soil solution range between 0.1 and $2 \mathrm{mmol} \mathrm{L}^{-1}$, depending on soil type, $\mathrm{CO}_{2}$ partial pressure and complexing organic acids (Marschner, 1995). Although $\mathrm{Si}$ is one of the fundamental elements, it has received relatively little attention in soil science compared to other elements (Sommer et al., 2006; Cooke and Leishman, 2011).

The main reason for disregarding the role of $\mathrm{Si}$ is that $\mathrm{Si}$, although being a quantitatively major inorganic constituent of higher plants (1 to $160 \mathrm{mg} \mathrm{g}^{-1}$; Raven, 1983; Epstein, 1994; Marschner, 1995), is not essential for their growth except for members of Equisetaceae (Epstein, 1994). Nevertheless, plants benefit in several ways from $\mathrm{Si}$, which therefore was called "quasi essential" by Epstein (1999).

Higher plants take up $\mathrm{Si}$ in the form of monomeric silicic acid and accumulate it primarily as amorphous silica (Opal A; $\mathrm{SiO}_{2} \cdot \mathrm{n} \mathrm{H}_{2} \mathrm{O}$; Neumann, 2003). The uptake mechanisms vary among plant species and are either passive (by mass flow of water) or active, allowing a distinction between $\mathrm{Si}$ accumulators (Si uptake >> water uptake) and Si nonaccumulators (Si uptake similar as or less than water uptake), besides Si excluders. Increasing $\mathrm{Si}$ accumulation by plants entails increased Si supply.

Precipitations of $\mathrm{Si}$ in roots, stems, branches, leaves, and needles are defined as phytogenic Si. Phytoliths, i.e., phytogenic Si precipitates with a size of $5 \mu \mathrm{m}$ to $200 \mathrm{~mm}$ (Sommer et al., 2006), probably contribute the major part of biogenic Si in soils (Clarke, 2003), with contents mostly between 1 and $30 \mathrm{mg} \mathrm{g}^{-1}$ of fine earth $(<2 \mathrm{~mm})$. Transport and incorporation into plant tissue strongly influences weathering and ecosystem cycling of Si (Alexandre et al., 1997): In general, phytogenic Si shows high solubility, and can be vertically and laterally transported within the soil. Especially undefined phytogenic Si $(<5 \mu \mathrm{m})$ has a high surface-to-volume ratio, thus high solubility (Bartoli, 1985; Fraysse et al., 2006) and probably plays a crucial role in Si fluxes within and from terrestrial biogeosystems (Sommer et al., 2006).

This leads to the question, which of the potential Si forms (amorphous on one hand, comprising mainly biogenic and pedogenic pools, vs. crystalline on the other hand, i.e., mineral pools) contribute to which extent to the Si fluxes. The Si cycle in the soil-plant system consists of Si mobilization in soil, Si uptake by plants, formation of phytogenic Si, and retranslocation to the soil by litterfall, as well as further pedogenic processes as, e.g., neoformation of clay-sized minerals. So far, the role and rate of $\mathrm{Si}$ uptake by higher plants, as well as its dependence on environmental factors like, e.g., $\mathrm{pH}$ of soil solution, is almost unknown (Ma and Takahashi, 2002). Evaluation of the effect of $\mathrm{pH}$ on Si availability in soil is crucial as it plays an important role for several pedogenic processes, including weathering and formation and disintegration of secondary clay minerals, as well as Si solubility.

We hypothesized that plants take up Si mainly from secondary amorphous Si phases because of its high reactivity. As Si is ubiquitous in all terrestrial biogeosystems, an experiment with wheat plants grown on artificial, Si-free substrate was performed and only one Si compound (either crystalline or amorphous) was added to elucidate from which pool wheat plants can take up $\mathrm{Si}$ to which amounts. Among these $\mathrm{Si}$ forms, properties of amorphous silica gel most strongly resemble those of phytogenic Si (see above). We further hypothesized that the rate of Si weathering and cycling is higher in planted than unplanted soil because of the effect of root exudates, transpirational pull of plants and active $\mathrm{Si}$ uptake by roots and consequently disequilibrium between dissolved and solid Si compounds. Therefore, also treatments without plants were applied. The aims were to (1) estimate Si-uptake rates for young wheat plants, (2) reveal the influence of various Si pools on these rates, and to (3) test whether $\mathrm{pH}$ influences Si-uptake rates. Therefore, Si-uptake rates estimated based on accumulated Si (real Si-uptake rates) were compared to those estimated from theoretical Si accumulation according to the volume of consumed nutrient solution (theoretical Si-uptake rates).

\section{Materials and methods}

\subsection{Experimental design}

Wheat (Triticum aestivum L.) was chosen for the experiment because it is a Si accumulator (Jarvis, 1987), i.e., wheat plants take up more Si than Si-nonaccumulator plants do based on water uptake and thus transpirational pull (Raven, 1983). By choosing a Si accumulator it was easier to test the effect of roots on Si dissolution.

Rates of Si uptake were estimated for various Si pools: Quartz sand (99\% $\mathrm{SiO}_{2}$; grain size 0.4-0.8 mm; Roth, Germany) and anorthite powder $\left(\mathrm{CaAl}_{2} \mathrm{Si}_{2} \mathrm{O}_{8} ;\right.$ grain size $<63 \mu \mathrm{m} ; 21.6 \%$ $\mathrm{SiO}_{2}$; Keramik-Kraft, Germany) were chosen as crystalline $\mathrm{Si}$ pools, silica gel granulate $\left(99.5 \% \quad \mathrm{H}_{4} \mathrm{SiO}_{4}\right.$; grain size 0.5-1 mm; Roth, Germany) as amorphous Si pool. The fourth treatment without Si pool was included for control (Fig. 1).

To test the effect of $\mathrm{pH}$ on $\mathrm{Si}$ uptake by plants, all treatments were adjusted to $\mathrm{pH} 4.5$ or $\mathrm{pH} 7$.

Seven days after planting, three replications of each treatment were harvested and analyzed for Si contents in aboveground biomass, root biomass, and nutrient solution. In total, the experiment included four sampling dates, performed in intervals of $7 \mathrm{~d}$.

Additionally, controls with same conditions and without plants were included to analyze the temporal change of Si concentration in solution without plant effects. These control pots were sampled nondestructive in the same time intervals like planted pots. 


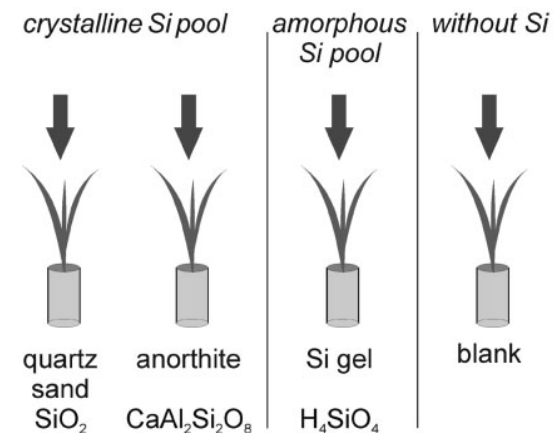

Hoagland nutrient solution, $\mathrm{pH} 4.5$

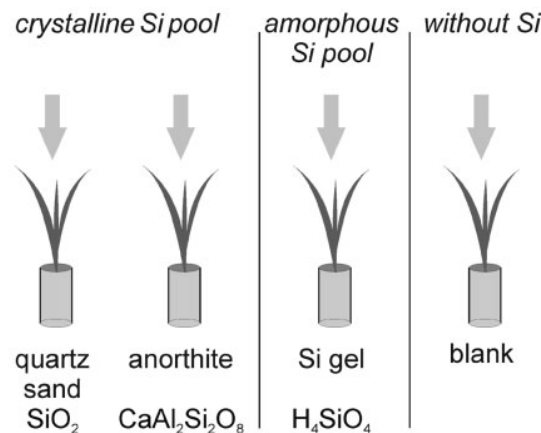

Hoagland nutrient solution, $\mathrm{pH} 7$
Figure 1: Experimental design, performed with four Si variants including three Si pools and one Si-free treatment, and two $\mathrm{pH}$ values.

\subsection{Growing conditions}

After pregermination for $2 \mathrm{~d}$, seedlings were transferred to $50 \mathrm{~mL}$ polypropylene centrifugation tubes (VWR, USA), filled with $35 \mathrm{~g}$ Si-free pellets (low-density polyethylene; pellet size $\approx 2 \mathrm{~mm}$; Hostalen GC 7260; LyondellBasell, The Netherlands) and $25 \mathrm{~mL}$ nutrient solution. Pellets were either applied without $\mathrm{Si}$ or mixed with $5 \mathrm{~g}$ of quartz sand, anorthite powder, or silica gel granulate. Per plant pot, the total $\mathrm{Si}$ content from the added Si pool was $2.34 \mathrm{~g}, 1.01 \mathrm{~g}, 1.46 \mathrm{~g}$, and $0 \mathrm{mg}$ for treatments with quartz, anorthite, silica gel, and without $\mathrm{Si}$, respectively. Different quantities of solid Si pools were added in the respective treatments because of their solubility, which reach a maximum very soon. The amounts of $\mathrm{Si}$ added exceed by far its solubility product, and consequently the $\mathrm{Si}$ in the solution is independent of the amount of $\mathrm{Si}$ in the solid phase. Each pot was planted with three seedlings and enveloped with Al-foil to avoid growth of algae within the pellet-root compartment.

To prevent evaporation, plant pots were closed by caps, with a hole of diameter $1.5 \mathrm{~cm}$ providing only space for shoot growth. Plants were grown for $28 \mathrm{~d}$ under controlled conditions of $14 / 10 \mathrm{~h}$ day/night periods, $20^{\circ} \mathrm{C}$, and light intensity of $300 \mu \mathrm{mol} \mathrm{m} \mathrm{m}^{-2} \mathrm{~s}^{-1}$. For nutrient supply, plants were treated with Hoagland nutrient solution, which shows an original $\mathrm{pH}$ of 5.5 (Hoagland and Arnon, 1950). For the study, pH was adjusted to either 4.5 or 7 by addition of either $\mathrm{HCl}$ or $\mathrm{NaOH}$ solution. Nutrient solution (and deionized water) was added every two days to re-obtain a solution of $25 \mathrm{~mL}$ in each pot. At each watering, all pots received the same volume of nutrient solution, while the remaining individual water deficit of each plant pot was compensated with deionized water.

Roots of wheat plants were aerated by a membrane pump (Type SMG4, Gardner Denver Thomas GmbH, Germany) for 30 min every $2 \mathrm{~d}$ for oxygen supply. During the experiment, plants reached tillering stage.

\subsection{Sample preparation and analyses}

For control of plant growth, chlorophyll contents of wheat leaves were measured $7 \mathrm{~d}$ after planting and subsequently in intervals of $7 \mathrm{~d}$ by a chlorophyll meter (SPAD-502 Plus; Konica Minolta, Japan). Average values per plant pot show mean chlorophyll content from 10-12 measurements, performed on
4-6 leaves depending on plant age. A number of 30 SPAD units is approximately equivalent to a chlorophyll content of $300 \mu \mathrm{mol} \mathrm{m}^{-2}$ (Santos Nascimento and Marenco, 2010).

Plants chosen for harvest were treated with nutrient solution for the last time $1 \mathrm{~d}$ before analysis. At each sampling date, shoots were cut at the base, weighed, dried for $24 \mathrm{~h}$ at $60^{\circ} \mathrm{C}$ and weighed again. Roots were separated from pellets and solid $\mathrm{Si}$ compounds by tweezers, rinsed with deionized water, dried for $24 \mathrm{~h}$ at $60^{\circ} \mathrm{C}$ and weighed. Roots and shoots were milled in a planet-type ball mill using milling vessels and balls made from $\mathrm{ZrO}_{2}$. Sample aliquots of approximately $200 \mathrm{mg}$ were digested under pressure in PFA digestion vessels using a mixture of $2.5 \mathrm{ml} \mathrm{HNO}_{3}$ and $1 \mathrm{~mL} \mathrm{HF}$ at $220^{\circ} \mathrm{C}$ and $\approx 100$ bar (Ultra Clave II, MLS GmbH, Leutkirch, Germany). Nutrient solutions were filtrated with folded paper filters (Roth, Germany) to remove pellets, solid Si compounds, and fine-root hairs.

Silicon was measured by ICP-OES (Vista Pro, Varian Inc., Australia) using a HF-resistant sample introduction system, radial viewing of the plasma, and matrix-matched external calibration. The analyses were performed at "Landesanstalt für Landwirtschaftliche Chemie", Hohenheim University, Stuttgart.

As Si occurs ubiquitous, additionally background $\mathrm{Si}$ content of deionized water was measured.

\subsection{Calculations and statistics}

Based on Si contents in total biomass (shoots and roots), real Si-uptake rates $\left(\right.$ rate $\left._{\mathrm{R}}\right)$ were calculated for each sampling date as

rate $_{\mathrm{R}}=\Delta S i_{\text {bio }} /(\Delta$ biomass $\times \Delta t)$,

with $\Delta S i_{\text {bio }}=$ amount of silicon gained since last sampling, measured in biomass $(\mathrm{mg}), \Delta$ biomass $=$ amount of biomass gained since last sampling (g), $\Delta t=$ time between two samplings (d).

The study was performed with three replications per treatment and per plant. Mean values and standard errors of the mean are presented in figures. The sample set was tested for significance of differences between $\mathrm{Si}$ pools and $\mathrm{pH}$ using 
one-way ANOVA with a significance level of $\alpha=0.05$, followed by post hoc Scheffé test. Statistical analysis was carried out using STATISTICA for Windows (version 7.0, StatSoft Inc., Tulsa, USA).

\section{Results}

\subsection{Chlorophyll contents and biomass gain}

Chlorophyll contents showed constant values between 28 and 41 SPAD units at pH 7 independently from the Si pool. In contrast, values significantly increased from first to last sampling for the blank (22 to 42 SPAD) and quartz (21 to 39 SPAD) treatments at pH 4.5 (Fig.2a). Plants grown on anorthite at $\mathrm{pH} 4.5$ showed highest chlorophyll contents of up to 43 SPAD units, while lowest values of 15 SPAD units occurred for plants grown on silica gel at pH 4.5 (Fig. 2a).

During $28 \mathrm{~d}$ of plant growth, amounts of biomass increased in an approximately linear way (Fig. 2b, c). Plants showed always higher shoot biomass compared to root biomass, with a mostly stable root-to-shoot ratio between 0.4 and 0.6 (not shown here). At pH 4.5, plants grown on anorthite had higher amounts of biomass than those grown on other Si pools, while at $\mathrm{pH} 7$ all plants had similar amounts of biomass (Fig. 2b, c).

\subsection{Silicon contents in plant biomass and in nutrient solutions}

Between first and last sampling, Si contents in plants were between 1 and $26 \mathrm{mg}$ ( $\mathrm{g}$ dry biomass)-1 in shoots and between 0.4 and $17 \mathrm{mg} \mathrm{g}^{-1}$ in roots, usually with higher values in aboveground biomass compared to roots. In most treatments, Si contents did not show increasing or decreasing trends with time (Fig. 3a, b). Only for plants grown on quartz at $\mathrm{pH} 7, \mathrm{Si}$ contents in roots significantly increased from the first to the last sampling date. Highest $\mathrm{Si}$ contents always occurred in the silica-gel treatment, independent of $\mathrm{pH}$ and plant part, and lowest Si contents either in the quartz treatment (shoots) or in the Si-free treatment (roots; Fig. 3a, b). After $28 \mathrm{~d}$, shoots of wheat grown on silica gel had 13-14 times higher Si contents ( 23 and $19 \mathrm{mg} \mathrm{g}^{-1}$ at pH 4.5 and 7 , respectively) than those grown on quartz (1.6 and $1.5 \mathrm{mg}$ $\mathrm{g}^{-1}$ ). For roots, Si contents after $28 \mathrm{~d}$ were $26-28$ times higher in plants grown on silica gel ( 9 and $10 \mathrm{mg} \mathrm{g}^{-1}$ at $\mathrm{pH} 4.5$ and 7 , respectively) than in those grown without Si pool (0.3 an $0.4 \mathrm{mg} \mathrm{g}^{-1}$ ).

In nutrient solutions, $\mathrm{Si}$ concentrations ranged between 0.5 and $22.8 \mathrm{mg} \mathrm{L}^{-1}$, with highest concentrations in the silica-gel treatment at $\mathrm{pH}$ 4.5. At pH 7, in contrast, no significant differences occurred between treatments with different Si pools. In most treatments, a slight decrease of Si concentrations was
pH 4.5

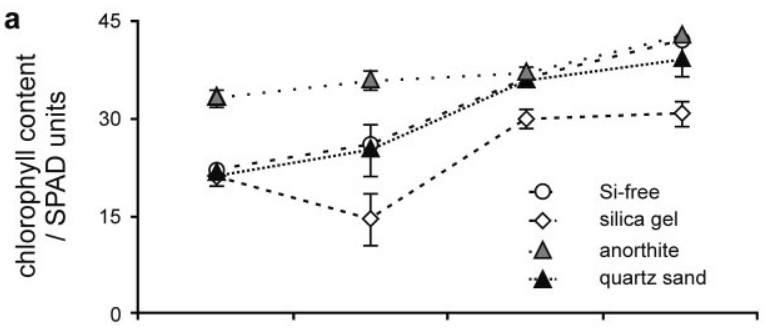

b

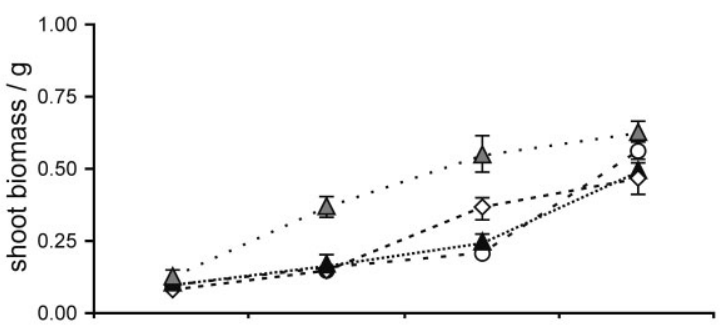

C

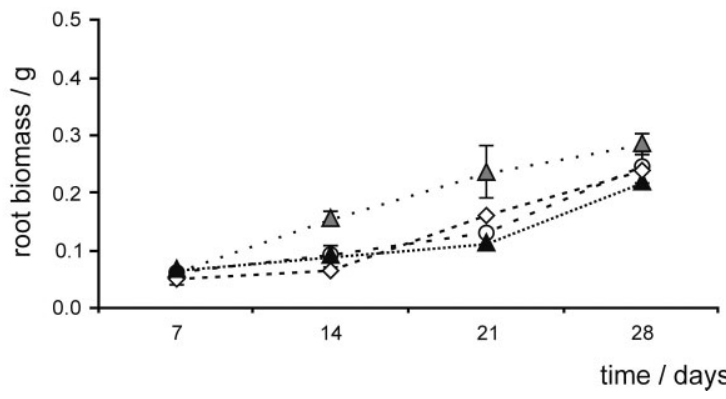

pH 7
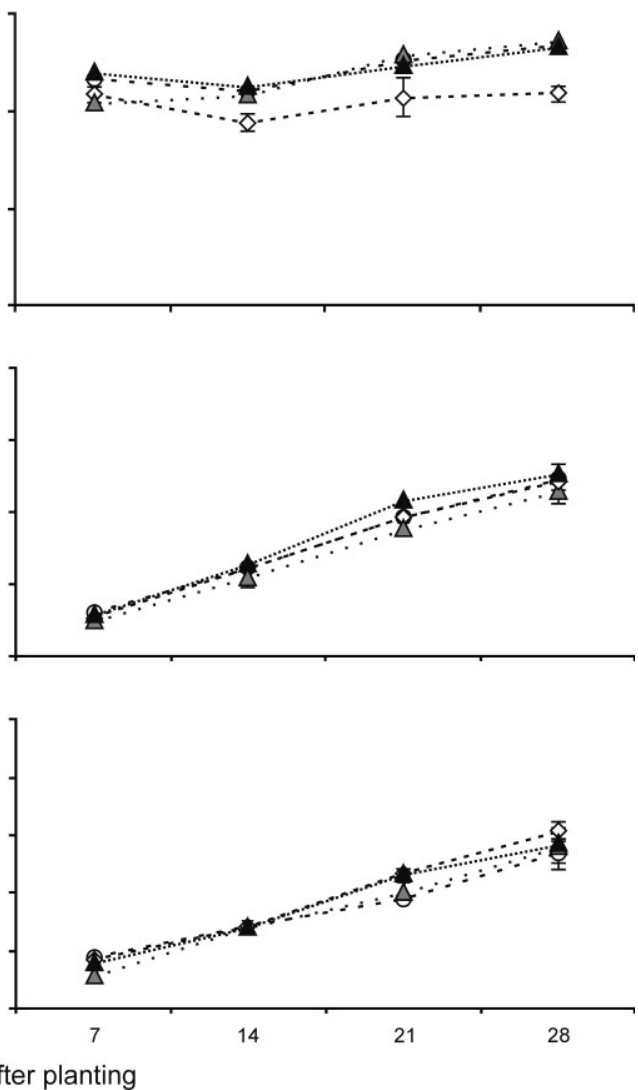

Figure 2: (a) Chlorophyll contents in leaves, amounts of (b) shoot and (c) root biomass of wheat plants grown on different Si pools, from first to last sampling for $\mathrm{pH} 4.5$ and $\mathrm{pH} 7$. 
pH 4.5
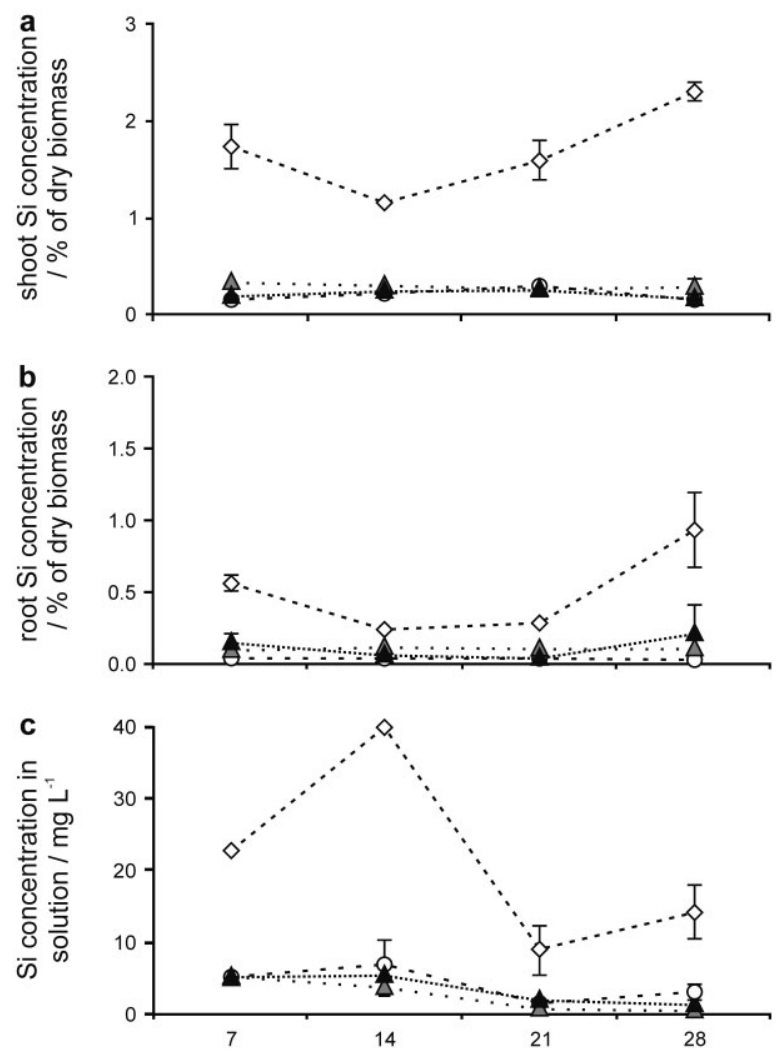

pH 7
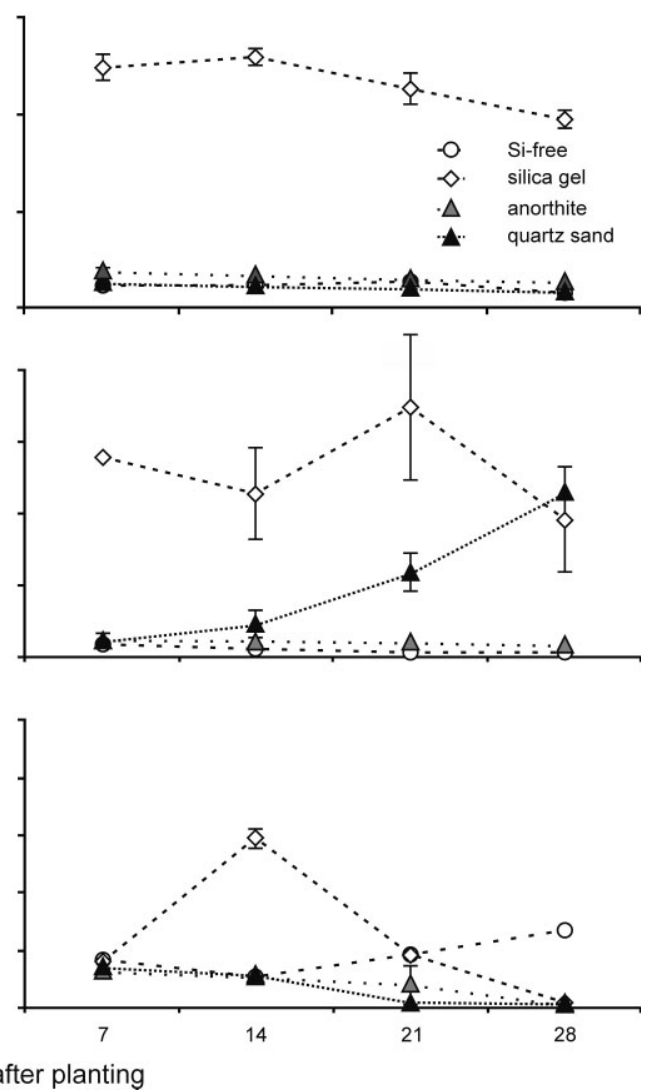

Figure 3: Silicon contents in (a) wheat leaves, (b) roots and (c) solutions from the planted pots with different Si pools, from first to last sampling for $\mathrm{pH} 4.5$ and $\mathrm{pH} 7$.

visible from the first to the last sampling date (Fig. 3c). However, different water consumption of individual plant pots, thus different volumes of solution remaining for analyses, led to high variations of $\mathrm{Si}$ concentrations. In addition, only total Si contents of the solutions were measured. These do not reveal the type of $\mathrm{Si}$ in solution (i.e., dissolved $\mathrm{Si}$, amorphous Si or, e.g., tiny grains of crystalline Si pools), i.e., whether the $\mathrm{Si}$ is plant-available. For instance, Watteau and Villemin (2001) showed that even particulate Si can pass paper filters.

For comparison, Si concentrations of the treatments without plants, averaged from four samplings, are given in Tab. 1. These were in the same order of magnitude as Si concentra-

Table 1: Silicon concentration ( $\mathrm{mg} \mathrm{L}^{-1}$ ) in solutions of the treatments without plants but with Hoagland nutrient solution, averaged from four sampling dates, as well as in deionized water.

\begin{tabular}{lcr}
\hline Si pool & pH 4.5 & \multicolumn{1}{c}{ pH 7 } \\
\hline quartz & $5.2 \pm 1.0$ & $2.3 \pm 0.5$ \\
anorthite & $4.5 \pm 0.5$ & $3.4 \pm 0.6$ \\
silica gel & $9.0 \pm 2.6$ & $20.3 \pm 1.6$ \\
Si-free & $5.4 \pm 0.8$ & $2.0 \pm 0.6$ \\
\hline deionized water & $<0.05$ & \\
\hline
\end{tabular}

tions of solutions of planted pots, ranging between 2.0 and $20.3 \mathrm{mg} \mathrm{L}^{-1}$. In the treatment without $\mathrm{Si}$, significant differences between $\mathrm{Si}$ concentrations of solutions of planted and unplanted pots occurred at $\mathrm{pH}$ 7. With silica gel, Si concentrations doubled at $\mathrm{pH} 7$ compared to $\mathrm{pH} 4.5$ (significant difference).

\subsection{Real Si-uptake rates}

Real Si-uptake rates, i.e., rates calculated based on Si contents of plant biomass, showed a wide range, with values of individual pots between 0.02 and $4.8 \mathrm{mg}$ Si per g biomass and per day. Independent of $\mathrm{pH}$, Si-uptake rates were always highest for plants grown on silica gel compared to all other treatments (Fig. 4a). There was no clear trend of increasing or decreasing Si-uptake rates with time except for the quartz treatment at $\mathrm{pH} 7$, where average values continuously increased from 0.3 to $1.4 \mathrm{mg} \mathrm{g}^{-1} \mathrm{~d}^{-1}$. At $\mathrm{pH} 4.5$, uptake rates strongly increased from the second to the fourth sampling (silica-gel treatment: from 1.2 to $3.0 \mathrm{mg} \mathrm{g}^{-1} \mathrm{~d}^{-1}$ ) or from the third to the fourth sampling (anorthite treatment: from 0.3 to $2.1 \mathrm{mg} \mathrm{g}^{-1} \mathrm{~d}^{-1}$; Fig. 4a). In those cases, however, loss of some samples precluded the significance test. In contrast, Siuptake rates were more or less constant during the experiment (blank and quartz treatments at $\mathrm{pH} 4.5$ ) or showed a slight decrease (blank and anorthite treatments at $\mathrm{pH} 7$ ). 
pH 4.5

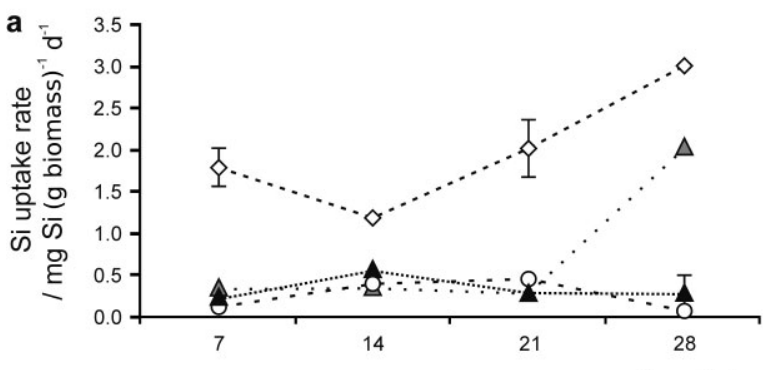

pH 7

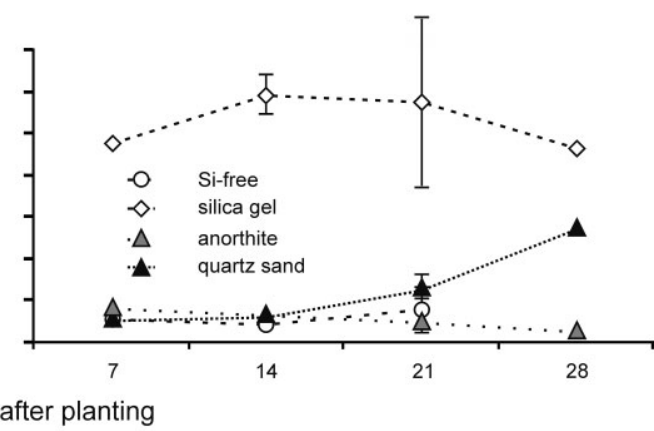

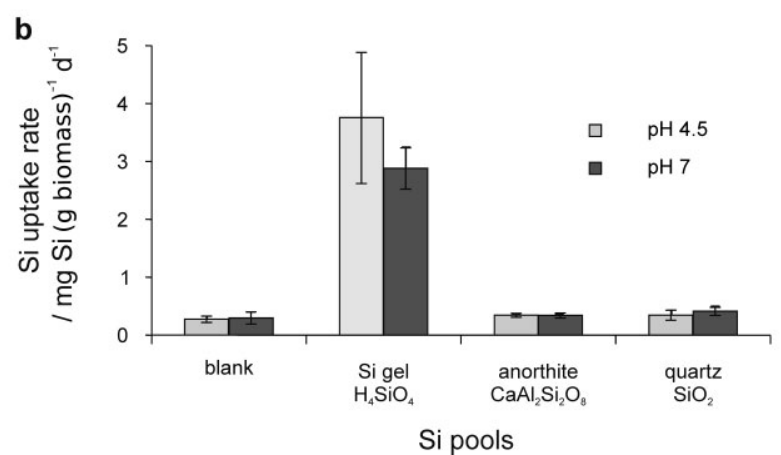

Figure 4: (a) Silicon-uptake rates for wheat grown on different Si pools for $\mathrm{pH} 4.5$ and pH 7. (b) Si-uptake rates (averaged from 4 sampling dates) from various Si pools at $\mathrm{pH} 4.5$ and $\mathrm{pH} 7$.

In general, average Si-uptake rates did not differ significantly for same Si pool between pH 4.5 and pH 7 (Fig. 4b), although values in the silica-gel treatment were higher at $\mathrm{pH} 4.5$ ([3.7 \pm 1.1] $\left.\mathrm{mg} \mathrm{g}^{-1} \mathrm{~d}^{-1}\right)$ compared to $\mathrm{pH} 7\left([2.9 \pm 0.4] \mathrm{mg} \mathrm{g}^{-1} \mathrm{~d}^{-1}\right)$.

\section{Discussion}

\subsection{Influence of Si pools and pH on plant growth}

As could be expected, plant growth was not identical on different Si pools. At pH 7, plants were growing well, independent of the Si pool. At pH 4.5 in contrast, anorthite led to best plant growth: Highest shoot and root biomass and chlorophyll contents occurred in this treatment, with values comparable to those at $\mathrm{pH} 7$, while the other treatments (blank, silica gel, and quartz) entailed slower plant growth (Fig. 2). Better and faster plant growth on anorthite led to lowest water content in shoots (not shown here) compared to the other four treatments at $\mathrm{pH} 4.5$, as the amount of water was equal and was equally adjusted.

In general, amounts of root and shoot biomass as well as chlorophyll contents suggest that at a neutral $\mathrm{pH}$, wheat growth is good and not strongly influenced by the applied $\mathrm{Si}$ form, whereas the latter likely exerts greater influence at $\mathrm{pH} 4.5$.

\subsection{Influence of Si pools and pH on Si contents and distribution in young wheat plants}

Despite the short duration of the experiment, $\mathrm{Si}$ contents in aboveground wheat biomass reached values typical for dryland species of Gramineae (10-30 $\mathrm{mg} \mathrm{g}^{-1}$; Fig. 3a; Hodson et al., 2005). For the silica-gel treatment, Si contents in leaves were comparable with those of previous studies: Jarvis (1987) determined a Si content of $17 \mathrm{mg} \mathrm{g}^{-1}$ in wheat grown for $27 \mathrm{~d}$ in Si solution with a Si concentration of $20 \mathrm{mg} \mathrm{L}^{-1}$.

However, this was not the case for treatments with Si pools other than silica gel. Silicon uptake by plants requires hydrolysis of $\mathrm{Si}$ compounds within the growing substrate (Ranganathan et al., 2006). Therefore, high Si contents in plants treated with silica gel can be explained by already dissolved $\mathrm{Si}$ which was available for root uptake. Mecfel et al. (2007) analyzed the effect of three $\mathrm{Si}$ forms (silica gel, completely dissociated $\mathrm{Na}_{4} \mathrm{SiO}_{4}$, and highly dispersed pyrolitic Si dioxide) on Si contents in leaves and stems of wheat plants. The highest Si content was measured in leaves fertilized with $\mathrm{Na}$ silicate, a soluble $\mathrm{Si}$ compound, followed by precipitated silica gel. They concluded that $\mathrm{Si}$ compounds which are easily converted to orthosilicic acid are most efficient for plant uptake.

For plants grown in artificial environment without Si addition, Si contents in plant biomass were lowest compared to other treatments (Fig. 3a, b), but average values did not differ significantly from treatments with crystalline $\mathrm{Si}$ sources. This shows the ubiquitous occurrence of $\mathrm{Si}$ even in deionized water. As water contains Si mainly as monomeric silicic acid, plants are able to take up and accumulate $\mathrm{Si}$ from this source. Additionally, Si contamination by dust during sample preparation cannot be completely excluded for the Si-free treatment.

In roots, Si contents were always considerably lower compared to aboveground biomass (Fig. 3a, b). This is because $\mathrm{Si}$ 
accumulates at the places of transpiratory water losses and consequently Si concentrates in leaves. This contributes to growth stability, fungal resistance, and further functions mainly in aboveground biomass (Marschner, 1995; Epstein, 1999; Ma and Yamaji, 2006; Nikolic et al., 2007).

At $\mathrm{pH} 7$, however, Si contents in roots showed different results, especially for plants treated with silica gel or quartz. With silica gel, roots reached nearly same maximum Si contents as leaves (17 $\mathrm{mg} \mathrm{g}^{-1}$ vs. $26 \mathrm{mg} \mathrm{g}^{-1}$, respectively). The reason remains unclear. Although absorption of Si colloids cannot be excluded, remainders of silica gel on the roots' surface can mostly be ruled out because silica gel is easily soluble in water compared to crystalline Si phases and thus was completely rinsed before analysis. Nearly identical Si contents in leaves and roots of these plants indicate the fastest plant availability of the silica gel compared to all other $\mathrm{Si}$ forms (Mecfel et al., 2007).

While Si contents in roots were mostly constant during the 4 weeks for all other treatments, Si content strongly increased from first to last sampling for plants treated with quartz at pH 7 (Fig. 3b). Remaining quartz sand on the roots is unlikely to have caused this. Instead, decreasing Si concentrations in the solutions (Fig. 3c), with lowest values compared to the other treatments at $\mathrm{pH} 7$, suggest that plants actually took up Si. However, this Si was stored in roots and not transferred to shoots. Likely, roots grew around small quartz grains without taking up the Si. Precipitation of Si can also occur in the xylem vessels and in the endodermis of roots (Raven, 1983).

No significant effects of $\mathrm{pH}$ on $\mathrm{Si}$ amounts and Si contents in plant biomass were found. The only difference was higher variation between various Si pools at $\mathrm{pH} 4.5$ (Fig. $2 \mathrm{a}-\mathrm{C}$ ). This shows increased weathering rates at low $\mathrm{pH}$. According to Tavakkoli et al. (2011), low pH leads to increased biomass production and increased Si uptake by rice. The authors compared amounts of shoot dry matter and Si contents at $\mathrm{pH}$ between 5.5 and 9.5. For a Red Ferrosol (natural pH 5.5), the strongest decrease in $\mathrm{Si}$ contents occurred between $\mathrm{pH} 5.5$ and 6.5, while for a Grey Vertosol (natural $\mathrm{pH} 7.1$ ), this was the case between $\mathrm{pH} 7.1$ and 9.5. Pedogenesis-reflected in soil type-likely plays a major role for the adsorption of $\mathrm{Si}$ components on soil particles like Al hydroxides and Fe oxides (e.g., Iler, 1979; Morris and Fletcher, 1987). Therefore, the uniform pellet substrate in the present study probably attenuated differences caused by $\mathrm{pH}$. The second reason might be the two chosen $\mathrm{pH}$ values in the present study, as silicic acid occurs in monomeric form - the only plant-available Si form in solution-at both pH 4.5 and 7(Iler, 1979; Drees et al., 1989; Dove, 1995). In contrast, higher solubility of both amorphous and crystalline Si pools are to be expected at $\mathrm{pH}<2.5$ and $>8.5$ (Dove, 1995).

\subsection{Comparison of real and theoretical Si-uptake rates}

Based on Si concentrations in solutions of unplanted pots, averaged from four sampling dates (Tab. 1), theoretical Si- uptake rates were calculated. In contrast to real Si-uptake rates, theoretical Si-uptake rates (rate ${ }_{T}$ ) were calculated based on consumption of nutrient solution and water, as well as Si contents of those, during the according time interval:

rate $_{\mathrm{T}}=\Delta S i_{\text {liquid }} /(\Delta$ biomass $\times \Delta t)$

with $\Delta S i_{\text {liquid }}=$ amount of silicon comprised in the volume of nutrient solution and water taken up by the plant since last sampling $(\mathrm{mg})$. These values therefore represent the amounts that plants would have taken up solely based on transpiration stream, i.e., in case of passive Si uptake.

At $\mathrm{pH} 4.5$, theoretical Si-uptake rates were highest for the quartz treatment $\left([2.3 \pm 1.5] \mathrm{mg} \mathrm{g}^{-1} \mathrm{~d}^{-1}\right)$, lower for silica gel $\left([1.3 \pm 0.4] \mathrm{mg} \mathrm{g}^{-1} \mathrm{~d}^{-1}\right)$, and lowest for treatments with anorthite $\left([0.8 \pm 0.2] \mathrm{mg} \mathrm{g}^{-1} \mathrm{~d}^{-1}\right)$ and without Si ([0.8 \pm 0.2$]$ $\mathrm{mg} \mathrm{g}^{-1} \mathrm{~d}^{-1}$; Fig. 5). In contrast at $\mathrm{pH} 7$, highest theoretical Siuptake rates occurred for plants treated with silica gel ([2.1 \pm $0.4] \mathrm{mg} \mathrm{g}^{-1} \mathrm{~d}^{-1}$ ), while rates in the treatments with crystalline Si pools were in the same range as those in treatments without Si (Fig. 5), i.e., between 0.5 and $0.7 \mathrm{mg} \mathrm{g}^{-1} \mathrm{~d}^{-1}$.

In the silica-gel treatment, independent from $\mathrm{pH}$, real uptake rates exceeded the theoretical uptake rates (Fig.5). This confirms the suggestion that Si uptake by wheat includes an active component (Liang et al., 2006; Rains et al., 2006). For all other treatments, the real Si-uptake rates were on average $40 \%$ smaller than the theoretical rates of the respective treatment with regard to Si pool and pH (Fig. 5), but insignificant.

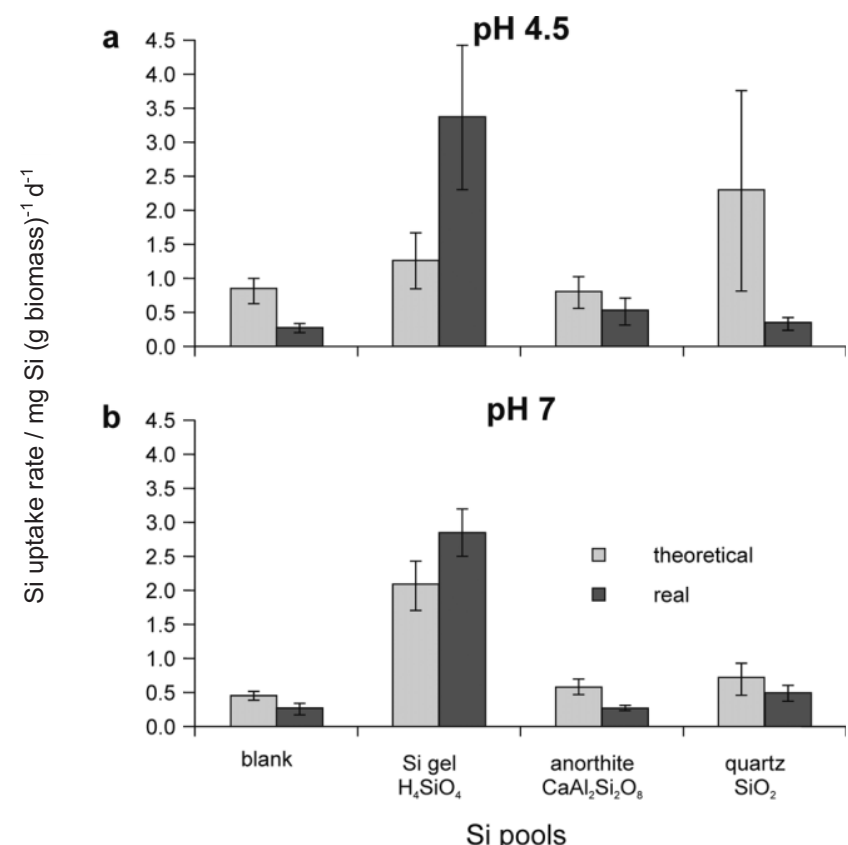

Figure 5: Comparison of theoretical Si-uptake rates, calculated based on water consumption, and real Si-uptake rates, calculated based on measured $\mathrm{Si}$ contents in biomass, from wheat grown on various Si pools at (a) $\mathrm{pH} 4.5$ and (b) $\mathrm{pH} 7$. 
Our results are partly in agreement with previous studies: Henriet et al. (2006) showed for banana plants, that plant growth was not influenced by the level of Si supply, similarly to the present study. The authors showed, however, that the rate of Si uptake by banana, as well as the Si content in plant biomass, were lowest (passive Si uptake) at high Si concentrations of the solution $\left(1.7 \mathrm{mmol} \mathrm{L}^{-1}\right)$ and higher than based on passive transport (active Si uptake) at lower Si concentrations $\left(0.02-0.8 \mathrm{mmol} \mathrm{L}^{-1}\right)$. This implies that plants in the study by Henriet et al. (2006) had to "make efforts" for Si uptake only in case of low Si availability. This was not the case in the present study: Highest average Si concentrations in solutions occurred in the treatments with silica gel (Fig. 3c), and there also the difference between theoretical and real uptake rates was highest compared to all other treatments, with the real Si-uptake rate being considerably higher (Fig. 5).

Differences between theoretical and real Si-uptake rates within each treatment were never significant, but generally were higher at $\mathrm{pH} 4.5$ than at $\mathrm{pH}$ 7: For plants grown on silica gel, for example, values of real Si-uptake rates were 2.7 times the theoretical values at $\mathrm{pH} 4.5$ and 1.4 times the theoretical values at $\mathrm{pH} 7$. These findings agree with previous studies on Si uptake: In a field study with wheat grown on a silt loam soil, Mayland et al. (1991) measured a 2.4- to 4.7fold higher real Si-uptake rate compared to theoretical Siuptake rates calculated based only on transpiration stream. Casey et al. (2003) showed that Si concentration in the xylem solution of mature wheat plants exceeded the Si concentration of the external solution by more than 400 already after exposing roots for $10 \mathrm{~min}$ to Si solution. For young wheat plants as in the present study, this factor might be even higher, as they have a high need for stability of tissues and protection against various stresses. It is well known that $\mathrm{Si}$ accumulation in wheat, occurring especially at the stomata, is controlled by active uptake and metabolic processes (Rains et al., 2006). For rice plants, a strong Si accumulator, for example, xylem loading (i.e., release of Si from cortical cells into the xylem) is the most important process for a high Si content in the shoots (Mitani et al., 2005). Subsequently, Si is transported to the shoot via xylem. Usually, Si concentration in the xylem sap of rice and wheat exceeds $2 \mathrm{mM}$, thus leading to polymerization of silicic acid to silica gel $\left(\mathrm{SiO}_{2} \cdot \mathrm{n} \mathrm{H}_{2} \mathrm{O}\right)$. Nevertheless, the major form of $\mathrm{Si}$ in the xylem has been identified as monomeric silicic acid (Mitani et al., 2005). In the shoot, silicic acid is further concentrated due to water loss (transpiration) and polymerized. With ongoing polymerization, silicic acid is converted into colloidal silicic acid and finally to silica gel with increasing silicic acid concentrations (Ma and Yamaji, 2006).

Independent from $\mathrm{pH}$, theoretical Si-uptake rates were similar or higher compared to real uptake rates. At $\mathrm{pH} 4.5$, the reason for that might be lower Si availability to plants, as Si concentrations in solution were low for all treatments except the silica gel. Solely plants grown on silica gel took up considerably more Si than merely based on transpiration stream, i.e., for these treatments real Si-uptake rates exceeded theoretical rates (Fig. 5). This confirms that plants are able to take up Si only in amorphous form. Short periods, in contrast, are not sufficient for conversion of crystalline pools into plant-available form.

\subsection{Comparison with literature and implications for the terrestrial Si cycle}

So far, mainly the effect of various Si concentrations in aqueous solutions on Si-uptake rates of higher plants was investigated. Therefore, plants were treated with various solutions either of monomeric silicic acid in solution (e.g., Jarvis, 1987; Casey et al., 2003; Tamei and Ma, 2003) or of Si-salt solution, usually $\mathrm{Na}_{2} \mathrm{SiO}_{3}$ (e.g., Liang et al., 2006; Rains et al., 2006). The latter is stable in neutral and alkaline solutions, but forms silicic acid in acidic solution and is then plant-available. Mecfel et al. (2007) compared Si accumulation in wheat grown on one of three types of Si pool: silica gel, Si-salt solution $\left(\mathrm{Na}_{2} \mathrm{SiO}_{3}\right)$, or pyrolitic fine silica particles. They showed that Si uptake from $\mathrm{Na}_{2} \mathrm{SiO}_{3}$ was most efficient, i.e., highest leaf Si contents of $23 \mathrm{mg} \mathrm{g}^{-1}$ were reached, and Si uptake from pyrolitic $\mathrm{SiO}_{2}$ was least efficient ( $\mathrm{Si}$ content $7 \mathrm{mg} \mathrm{g}^{-1}$ ). Uptake of Si from silica gel led to an intermediate leaf Si content of $16 \mathrm{mg} \mathrm{g}^{-1}$. Generally, these values are in a similar range like our results, with values $<5 \mathrm{mg} \mathrm{g}^{-1}$ for crystalline Si pools. However in our study, leaf Si contents $>20 \mathrm{mg} \mathrm{g}^{-1}$ were determined in plants grown on silica gel (Fig. 3a). The reason for higher leaf Si contents in the silica-gel treatment in our study compared to the study by Mecfel et al. (2007) might be the longer duration of the latter: As plant Si contents were measured at maturity, the rate of $\mathrm{Si}$ accumulation likely decelerated during longer plant growth, in comparison to young wheat plants with an age of 7-28 d as in our study.

Another study comparing the effect of various Si pools on $\mathrm{Si}$ uptake by higher plants was performed by Pereira et al. (2004) using rice plants. All Si pools in this study were inorganic (either crystalline like, e.g., wollastonite, or schist, or slag of various origin), and led to Si contents in aboveground biomass of $<8 \mathrm{mg} \mathrm{g}^{-1}$ after a growth period of 5 months. This is comparable to our results with crystalline Si pools (Fig. 3a), showing the low plant availability of the Si pools applied by Pereira et al. (2004).

Two obstacles occur for comparison of Si-uptake rates from the present study with literature: First, in field studies Si uptake of plants is often referred to area instead of plant biomass (e.g., Cornelis et al., 2010). Second, Si uptake of plants, measured either in plant biomass or by monotoring $\mathrm{Si}$ concentration in the culture solution, is usually related on dry weight of root biomass (e.g., Tamei and Ma, 2003), while in the present study, rates were calculated using total biomass within each individual plant pot (see Eq. 1). We made this decision because our short-term experiment showed that

Table 2: Silicon-uptake rates from wheat ( $\left.\mathrm{mg} \mathrm{g}^{-1} \mathrm{~d}^{-1}\right)$, averaged from four sampling dates. Values were calculated based on total-plant $\mathrm{Si}$ content and dry root biomass, in contrast to Si-uptake rates in Fig. 4.

\begin{tabular}{lll}
\hline Si pool & pH 4.5 & pH 7 \\
\hline quartz & $1.1 \pm 0.3$ & $1.7 \pm 0.3$ \\
anorthite & $1.5 \pm 0.4$ & $0.9 \pm 0.1$ \\
silica gel & $5.7 \pm 0.5$ & $8.6 \pm 1.2$ \\
without Si & $0.8 \pm 0.2$ & $1.2 \pm 0.5$ \\
\hline
\end{tabular}


roots are not solely the organ which takes up Si, but Si was also stored in roots. Therefore, total biomass should be taken into account. However, for purpose of comparison, Si-uptake rates from the present study were also calculated based on total Si content and dry root biomass (Tab. 2). In this case, highest Si-uptake rates of $8.6 \mathrm{mg} \mathrm{g}^{-1} \mathrm{~d}^{-1}$ were in the same range as values reported by Tamei and Ma (2003) of up to $\approx 10 \mathrm{mg} \mathrm{g}^{-1} \mathrm{~d}^{-1}$ for 17 -d-old wheat plants. Under field conditions, Si accumulation in Gramineae, like, e.g., wheat or ryegrass, depend on several factors like soil type, source of $\mathrm{Si}$, and, in case of fertilization, rate of Si application (Nanayakkara et al., 2008).

Our results indicate that plants like wheat, among other factors like neoformation and adsorption, can strongly contribute to the Si cycle in terrestrial biogeosystems. Biogenic (phytogenic) Si occurs in amorphous form. Our results with highest Si-uptake rates for plants grown on amorphous Si (silica gel, the Si pool with properties closest to those of phytogenic Si) strongly suggest that phytogenic $\mathrm{Si}$ is the most labile Si pool in grassland soils and contributes strongest to Si cycling-via uptake and litterfall-in terrestrial biogeosystems. This was already shown for grasses (Fraysse et al., 2006) and forest soils. Comparing Si-uptake rates of different tree species, Cornelis et al. (2010) pointed out the important role of biogenic Si and its recycling for the global Si cycle.

\section{Conclusions}

Within the tested $\mathrm{pH}$ range (4.5 and 7), the $\mathrm{pH}$ of the soil solution does not significantly affect Si-uptake rates of wheat. However, the form of applied Si has major influence: Among crystalline (quartz, anorthite) and amorphous (silica gel) Si pools, amorphous $\mathrm{Si}$ is the most effective Si form with highest plant availability under hydroponic conditions. Silicon-uptake rates of plants grown with silica gel were considerably higher than they would be solely based on water transpiration, demonstrating the active Si uptake from readily soluble amorphous $\mathrm{Si}$. This means that compared to the other applied Si pools, Si from silica gel is best plant-available, while solution of the other pools takes too long to be plant-available and accumulated in plant biomass within few weeks. These results support the hypothesis that amorphous $\mathrm{Si}$ is the soil Si pool with the highest turnover because of its high surfaceto-volume ratio, amorphous structure and high water solubility. This Si solubility may be increased by organic substances exuded by roots.

\section{Acknowledgments}

This study was financially supported by the German Research Foundation (Deutsche Forschungsgemeinschaft, DFG)_PAK 179 "Multiscale Analysis of Si Cycling in Terrestrial Biogeosystems". We thank Lyondell Basell for providing PE pellets for free, J. Breuer for analytical support, and $I$. Thaufelder for valuable assistance in the laboratory. Useful comments and supplements on the study and the manuscript provided by $U$. Beyersdorf and G. L. B. Wiesenberg are gratefully acknowledged.

\section{References}

Alexandre, A., Meunier, J. D., Colin, F., Koud, J. M. (1997): Plant impact on the biogeochemical cycle of silicon and related weathering processes. Geochim. Cosmochim. Acta 61, 677-682.

Bartoli, F. (1985): Crystallochemistry and surface properties of biogenic opal. J. Soil Sci. 36, 335-350.

Berner, R. A. (1997): The rise of plants and their effect on weathering and atmospheric $\mathrm{CO}_{2}$. Science 276, 544-546.

Casey, W. H., Kinrade, S. D., Knight, C. T. G., Rains, D. W., Epstein, E. (2003): Aqueous silicate complexes in wheat Triticum aestivum L.. Plant, Cell and Environment 27, 51-54.

Clarke, J. (2003): The occurence and significance of biogenic opal in the regolith. Earth-Science Revisions 60, 175-194.

Cooke, J., Leishman, M. R. (2011): Is plant ecology more siliceous than we realise? Trends Plant Sci. 16, 61-68.

Cornelis, J. T., Ranger, J., Iserentant, A., Delvaux, B. (2010): Tree species impact the terrestrial cycle of silicon through various uptakes. Biogeochem. 97, 231-245.

Dove, P. M. (1995): Kinetic and Thermodynamic Controls on Silica Reactivity in Weathering Environments, in White, A. F., Brantley, S. L. (eds.): Chemical Weathering Rates of Silicate Minerals. Rev. in Mineralogy 31, Mineralogical Society of America, Washington D. C., pp. 235-290.

Drees, L. R., Wilding, L. P., Smeck, N., Sankayi, A. L. (1989): Silica in Soils: Quartz and Disordered Silica Polymorphs, in Dixon, J. B., Weed, S. B. (eds.): Minerals in Soil Environments. SSSA Book series No. 1, Madison, WI, USA, pp. 913-974.

Epstein, E. (1994): The anomaly of silicon in plant biology. Proceed. Nat. Acad. Sci. 91, 11-17.

Epstein, E. (1999): Silicon. Annu. Rev. Plant Physiol. Plant Mol. Biol. 50, 641-664.

Fraysse, F., Pokrovsky, O. S., Schott, J., Meunier, J.-D. (2006): Surface properties, solubility and dissolution kinetics of bamboo phytoliths. Geochim. Cosmochim. Acta 70, 1939-1951.

Gerard, F., Francois, M., Ranger, J. (2002): Processes controlling silica concentration in leaching and capillary soil solutions of an acidic brown forest soil (Rhone, France). Geoderma 107, 197-226.

Henriet, C., Draye, X., Oppitz, I., Swennen, R., Delvaux, B. (2006): Effects, distribution and uptake of silicon in banana (Musa spp.) under controlled conditions. Plant Soil 287, 359-374.

Hoagland, D. R., Arnon, D. I. (1950): The water-culture method for growing plants without soil. California Agricultural Experiment Station Circular 347, 1-32.

Hodson, M. J., White, P. J., Mead, A., Broadley, M. R. (2005): Phylogenetic variation in the silicon composition of plants. Ann. Bot. 96, 1027-1046.

Iler, R. K. (1979): The Chemistry of Silica - Solubility, Polymerization, Colloid and Surface Properties, and Biochemistry. Wiley \& Sons, New York, p. 866.

Jarvis, S. C. (1987): The uptake and transport of silicon by ryegrass and wheat. Plant Soil 97, 429-437.

Kump, L. R., Brantley, S. L., Arthur, M. A. (2000): Chemical weathering, atmospheric $\mathrm{CO}_{2}$ and climate. Annu. Rev. Earth Planet. Sci. 28, 611-667.

Liang, Y., Hua, H., Yhu, Y. G., Yhan, J., Cheng, C., Römheld, V. (2006): Importance of plant species and external silicon concentration to active silicon uptake and transport. New Phytologist 172, 63-72. 
Ma, J. F., Takahashi, E. (2002): Soil, Fertilizer, and Plant Silicon Research in Japan. Elsevier Science, Amsterdam, The Netherlands.

Ma, J. F., Yamaji, N. (2006): Silicon uptake and accumulation in higher plants. Trends Plant Sci. 11(8), 392-397.

Marschner, H. (1995): Mineral Nutrition of Higher Plants. Academic Press, San Diego, CA, USA.

Mayland, H. F., Wright, J. L., Sojka, R. E. (1991): Silicon accumulation and water uptake by wheat. Plant Soil 137, 191-199.

Mecfel, J., Hinke, S., Goedel, W. A., Marx, G., Fehlhaber, R., Bäucker, E., Wienhaus, O. (2007): Effect of silicon fertilizer on silicon accumulation in wheat. J. Plant Nutr. Soil Sci. 170, 769-772.

Mitani, N., Ma, J. F., Iwashita, T. (2005): Identification of the Silicon Form in Xylem Sap of Rice (Oryza sativa L.). Plant Cell Physiol. 46, 279-283.

Monger, H. C., Kelly, E. F. (2002): Silica Minerals, in Dixon, J. B., Schulze, D. G. (eds.): Soil Mineralogy with Environmental Applications. Book Series SSSA No.7, Madison, WI, USA, pp. 611-636.

Morris, R. C., Fletcher, A. B. (1987): Increased solubility of quartz following ferrous-ferric iron reactions. Nature 330, 558-561.

Nanayakkara, U. N., Uddin, W., Datnoff, L. E. (2008): Application of silicon sources increases silicon accumulation in perennial ryegrass turf on two soil types. Plant Soil 303, 83-94.

Nikolic, M., Nikolic, N., Liang, Y., Kirkby, E. A., Römheld, V. (2007): Germanium-68 as an adequate tracer for silicon transport in plants. Characterization of silicon uptake in different crop species. Plant Physiol. 143, 495-503.

Neumann, D. (2003): Silicon in Plants, in Müller, W. E. G. (ed.): Silicon Biomineralization. Springer Verlag, Berlin, pp. 149-162.
Pereira, H. S., Korndörfer, G. H., de Aquino Vidal, A., Sartori de Camargo, M. (2004): Silicon sources for rice crop. Sci. Agric. 61, 522-528.

Rains, D. W., Epstein, E., Zasoski, R. J., Aslam, M. (2006): Active silicon uptake by wheat. Plant Soil 280, 223-228.

Ranganathan, S., Suvarchala, V., Rajesh, Y. B. R. D., Srinivasa Prasad, M., Padmakumari, A. P., Voleti, S. R. (2006): Effects of silicon sources on its deposition, chlorophyll content and disease and pest resistance in rice. Biol. Plant. 50, 713-716.

Raven, J. A. (1983): The transport and function of silicon in plants. Biol. Rev. 58, 179-207.

Santos Nascimento, H. C., Marenco, R. A. (2010): SPAD-502 readings in response to photon fluence in leaves with different chlorophyll content. Rev. Ceres, Viçosa 57, 614-620.

Sommer, M., Kaczorek, D., Kuzyakov, Y., Breuer, J. (2006): Silicon pools and fluxes in soils and landscape - a review. J. Plant Nutr. Soil Sci. 169, 310-329.

Tamei, K., Ma, J. F. (2003): Characterization of silicon uptake by rice roots. New Phytologist 158, 431-436.

Tavakkoli, E., Lyons, G., English, P., Guppy, C. N. (2011): Silicon nutrition of rice is affected by soil $\mathrm{pH}$, weathering and silicon fertilisation. J. Plant Nutr. Soil Sci. 174, 437-446.

Tréguer, P., Nelson, D. M., van Bennekorn, A. J., DeMaster, D. J., Leynaert, A., Quéguiner, B. (1995): The silica balance in the world ocean: a reestimate. Science 268, 375-379.

van Breemen, N., Buurman, P. (2002): Soil formation. Kluwer Academic Press, Dordrecht.

Watteau, F., Villemin, G. (2001): Ultrastructural study of the biogeochemical cycle of silicon in the soil and litter of a temperate forest. Eur. J. Soil Sci. 52, 385-396.

Wedepohl, K. H. (1970): Handbook of Geochemistry. Volume II/2. Springer, Berlin, Heidelberg, New York. 